\title{
Structural and Functional Characteristics of Microplastic Associated Biofilms in Response to Temporal Dynamics and Polymer Types
}

\author{
Chen $\mathrm{Tu}^{1,2} \cdot$ Ying Liu $^{1} \cdot{\text { Lianzhen } \mathrm{Li}^{1} \cdot \text { Yuan } \mathrm{Li}^{1} \cdot \text { Angela Vogts }^{2} \cdot \text { Yongming Luo }^{1,3} \text { (D) Joanna J. Waniek }}^{2}$
}

Received: 21 May 2021 / Accepted: 9 July 2021

(c) The Author(s), under exclusive licence to Springer Science+Business Media, LLC, part of Springer Nature 2021

\begin{abstract}
The colonization of bacterial communities and biofilm formation on microplastics (MPs) have aroused great concern recently. However, the influence of time and polymer types on the structural and functional characteristics of biofilms remains unclear. In this study, three types of MPs (polyethylene, polypropylene, and polystyrene) were exposed for different time periods (10, 20 and 30 days) in seawater using a microcosm experiment. Microscopic spectroscopy and high-throughput gene sequencing techniques were used to reveal the temporal changes of structural and functional characteristics of MPs associated biofilms. The results indicate that the biofilm formation is affected by both the incubation time and the polymer type. In addition, bacterial diversity and community structure in the biofilms show selectivity towards seawater, and tend to shift over time and among different polymer types. Moreover, biofilms are shown to harbor plastic degrading bacteria, leading to the changes of functional groups and surface hydrophobicity, and thereby enhancing the biodegradation of MPs.
\end{abstract}

Keywords Microplastics $\cdot$ Biofilm $\cdot$ Morphology and structure $\cdot$ Microbial community $\cdot$ Biodegradation

Microplastics (MPs) are defined as fine plastics less than $5 \mathrm{~mm}$ in size, which include produced small-sized particles (primary source) and particles originating from secondary sources like degradation or fragmentation of large plastics (Cole et al. 2011; Oberbeckmann and Labrenz 2020). Over the past decade, a rapidly growing number of studies reported the occurrence of MPs in marine, freshwater, soil, air, as well as coastal and remote regions like polar ecosystems, remote mountains and deep sea trenches (Cunningham et al. 2020; He and Luo 2020; Van Cauwenberghe et al. 2013; Wright et al. 2020a; Wright et al. 2020b; Yan et al. 2020). Due to their small size and ubiquitous distribution,

Yongming Luo

ymluo@issas.ac.cn

1 CAS Key Laboratory of Coastal Environmental Processes and Ecological Remediation, Yantai Institute of Coastal Zone Research (YIC), Chinese Academy of Sciences (CAS); Shandong Key Laboratory of Coastal Environmental Processes, YICCAS, Yantai 264003, China

2 Leibniz Institute for Baltic Sea Research, 18119 Rostock, Germany

3 CAS Key Laboratory of Soil Environment and Pollution Remediation, Institute of Soil Science, Chinese Academy of Sciences, Nanjing 210008, China
MPs has been proven to be taken up by many aquatic and terrestrial organisms, including plants, benthos, plankton, invertebrates and vertebrates (Amaral-Zettler et al. 2020; Li et al. 2020; Zhu et al. 2019). Thus, MPs are posing an emerging environmental and ecological risk in both aquatic and terrestrial ecosystems.

In addition to the uptake, ingestion and translocation of MPs by higher trophic level organisms, the adsorption and biofouling of microorganisms on the surface of MPs is attracting increasing research interests. Benefiting from the large specific surface area and ideal buoyant density, MPs are considered as novel habitats for microbial organisms named "plastisphere" (Zettler et al. 2013). MPs provide ideal niches for a variety of microorganisms in aquatics environments (Arias-Andres et al. 2019; Yang et al. 2020), which is conducive to the colonization of microorganisms and the formation of biofilms. Early studies of the plastisphere based on scanning electron microscopy (SEM) indicated that, many microorganisms, especially bacteria and fungi that colonized and thrived on the surface of MPs prefer an attached life style of biofilms (McCormick et al. 2014). Biofilms are defined as aggregates of cells that are frequently embedded within a matrix of extracellular polymeric substances adhere to each other and/or to the surface. A series of techniques and facilities have been applied in the qualitative and 
quantitative analyses of MPs associated biofilms, including crystal violet assay (CVA), SEM, confocal laser scanning microscopy (CLSM), flow cytometry, and high-throughput DNA sequencing (Tu et al. 2020a, b). With the help of these methodologies, the community structure and potential functions of biofilms attached on MPs have been gradually revealed. Formation of biofilms has been considered potentially to change the morphological and physicochemical properties of MPs in the marine environment, thus leading to a series of complex impacts on the environmental fate of MPs such as horizontal and vertical displacement, combined toxicities with pollutants and pathogens, as well as weathering and degradation (Zettler et al. 2013).

Despite noteworthy advances in this field, key questions remain unclear and important knowledge gaps exist (Amaral-Zettler et al. 2020). How does the structure and function of MPs associated biofilm evolve over time periods lasting few days to a month? Does the plastic type play a role? Our previous study has described the effects of longterm exposure (135 days) on the biofilm formation on polyethylene microplastics (Tu et al. 2020b). In this study, a microcosm experiment was conducted with the aims to (1) reveal the changes of biomass and morphology of biofilms on three types of MPs over short time scale (up to 30 day); (2) identify the core bacterial communities dominating the biofilms of the plastisphere, and clarify their succession dynamics; (3) explore the naturally occurring plastic degrading bacteria in the biofilms and verify their potential for MPs-degrading capacity. Our study seek to fill the gap in uncovering the functions of microorganism-microplastic interaction in the marine ecosystem.

\section{Materials and Methods}

Three different types of MPs, polyethylene (PE) films $(5 \mathrm{~mm} \times 5 \mathrm{~mm})$, polypropylene $(\mathrm{PP})$ pellets $(3-5 \mathrm{~mm})$ and expanded polystyrene (EPS) foams (3-5 mm) were selected to investigate the temporal development of microbial colonization and biofilm formation in a microcosm experiment. About 100 pieces of each type of MPs were separately filled in a nylon bag (pore diameter $0.15 \mathrm{~mm}$ ) with 3 replicates, and all the nylon bags were submerged in a glass tank $(40 \mathrm{~cm} \times 30 \mathrm{~cm} \times 30 \mathrm{~cm})$ filled with $20 \mathrm{~L}$ unfiltered seawater collected from the Heiligendamm Pier site at the coast of the Baltic Sea close to Rostock, Germany in June, 2019. The temperature and salinity of the seawater were $15.3^{\circ} \mathrm{C}$ and 11.6 , respectively. The microcosm experiment was covered with aluminum foil, standing statically on the window sill of the laboratory at room temperature (around $20^{\circ} \mathrm{C}$ ). The average daylight and average sunshine hours of Warnemünde, where the microcosm experiment was conducted, are $16.6 \mathrm{~h}$ and $9.1 \mathrm{~h}$ in July, and the average UV index is 5 . The sunlight could reach the water and the outside of the nylon bags in the glass tank. Periodic sampling was conducted after 10, 20 and 30 days of incubation, to visualize and quantify the morphology, composition and bacterial community structure of biofilm attached onto different types of MPs. All the details of are given in Tu et al. (2020b) and are just briefly summarized here.

Crystal violet assay was used to quantify the total amount of biofilms (biomass) formed on the surface of MPs (Lobelle and Cunliffe 2011). Three pieces of MPs were placed into a sterile petri dish and stained with $1 \%$ crystal violet solution. The stain was decolorized with $95 \%$ ethanol solution and the absorbance was subsequently measured using a UV-Visible spectrophotometer (Thermo Fisher GENESYS $10 \mathrm{~S}, \mathrm{US}$ ) at $595 \mathrm{~nm}$. Commercial pristine MPs were used as a control group to show the adsorption of crystal violet dye on the pristine microplastics, and were subtracted from all the experimental groups to obtain the final absorbance value for all the MPs samples. Each treatment was replicated three times.

The morphology of the biofilm on the surfaces of the MPs were observed by SEM (Zeiss Merlin Compact, Germany). MPs samples were fixed with $2.5 \%$ glutaraldehyde and were gradually dehydrated in 50\%, 70\%, 90\% and $100 \%$ ethanol. After the sample was dry, the sample surface was sprayed with carbon for SEM observation.

The temporal composition and 3D structure of the biofilm formed on the PE film surface was observed by CLSM (Tu et al. 2020b). Briefly, three PE films from each incubation time were stained with different fluorescent dyes (SYTO9, prodium iodide, and Concanavalin A) for $30 \mathrm{~min}$ in the dark. The films were rinsed with sterile water 3 times before placing on a coverslip and observed by CLSM (Olympus FV1000, Japan). Three sets of lasers were used for the fluorescent dyes excitation at the wavelengths of 488,559 , and $633 \mathrm{~nm}$, respectively. Fluorescent images were obtained and analyzed by the Olympus FV10-ASW software.

Twenty one samples were sequenced successfully including PE, PP and EPS microplastics with the incubation time for 10 and 30 days, as well as the surrounding seawater. Each treatment was replicated three times in parallel. Total DNA of the MPs associated biofilm was extracted using the MP FastDNA® kit for soil. The 515FmodF and 806RmodR primers were used to amplify the V4 hypervariable region of 16S rRNA gene (Walters et al. 2015). High-throughput DNA sequencing by the Illumina MiSeq platforms was conducted at Shanghai Majorbio Bio-pharm Technology Co., Ltd. (Shanghai, China). Quality control and bioinformatics analysis of the raw data were performed using the Majorbio Cloud Platform. All the sequencing data have been submitted to the National Center for Biotechnology Information (NCBI) database with the accession number SRP326263. 
Changes of functional chemical groups on the surface of MPs after biofilm formation were characterized using a Fourier transform infrared spectrometer (FTIR, Thermo Fisher Nicolet iS10, US). The samples were washed with $2 \%(\mathrm{w} / \mathrm{v})$ sodium dodecyl sulfate (SDS) solution to remove biofilms and air dried before FTIR analysis (Yang et al. 2014). The samples were scanned with a resolution of $4 \mathrm{~cm}^{-1}$ and a spectrum setting range of $650-4000 \mathrm{~cm}^{-1}$. All spectra were processed using the OMNIC 32 software. Water contact angle measuring device (DataPhysics OCA50, Germany) was used to evaluate the change in hydrophobicity of the PE MPs caused by the growth of biofilm. The static contact angle of water droplets on the surface of the PE film was fitted using the SCA20 software. Pristine PE films were also tested as a control, and each experiment was set in three parallels.

All the data analysis and statistics were performed using the Origin 9.0 and Microsoft Excel 2020. The differential significance analysis among different treatments was performed by one-way analysis of variance from the SPSS 26.0 software.

\section{Results and Discussion}

Quantification of the biofilm formed on the surface of different MPs was performed by crystal violet colorimetric analysis after 10, 20 and 30 days of incubation (Fig. 1). Despite the biomass of biofilms associated with all the three MPs showed an overall increasing trend with time, the capability of bacterial colonization and early biofilm formation on
EPS was significantly higher than that on PE and PP after 10 days. Since then, biofilms on PE and PP grown rapidly, and were almost equal to the EPS level at the end of the incubation (30 days). Ogonowski et al. (2018) indicated that the hydrophobicity of polymer could affect the bacterial composition but not abundance of the MP associated biofilms, particularly during the first stages of the colonization. Our results confirmed this hypothesis.

The morphology of the biofilm development on the surfaces of different MPs was observed by SEM. Following the previous development of biomass, the density of the biofilm on all three MPs surfaces increased over the incubation time (Fig. 2). Moreover, the microorganisms showed an enhanced colonization and biofilm forming capability on EPS in comparison to PE and PP. A variety of morphological types of biofilm were observed on the surface of MPs, including rod, short rod, oval and filamentary shaped bacteria and fungi, as well as the extracellular polymeric substances surrounding some of the bacterial cells. The presence of the blanket like extracellular polymeric substances on-top of the bacteria colonizing the surface of PE at day 10 (top left of Fig. 2) indicates that these bacteria may have utilized the PE as the carbon and energy source to drive the biofilm formation (Oliveira et al. 2021). The SEM results showed that polymer components and the time for the interaction of MPs and colonizing microbes could synergistically affect the morphological characteristics of the biofilms. This is in accord with the CVA results.

Furthermore, biofilm composition and 3D structure were visually analyzed by CLSM. Due to the unsuitable shape of PP (particles) and EPS (pellets) samples, only PE
Fig. 1 Variations of the biofilm biomass on three types of MPs over time. Different lowercase letters on top of the error bars indicate significant differences $(p<0.05)$

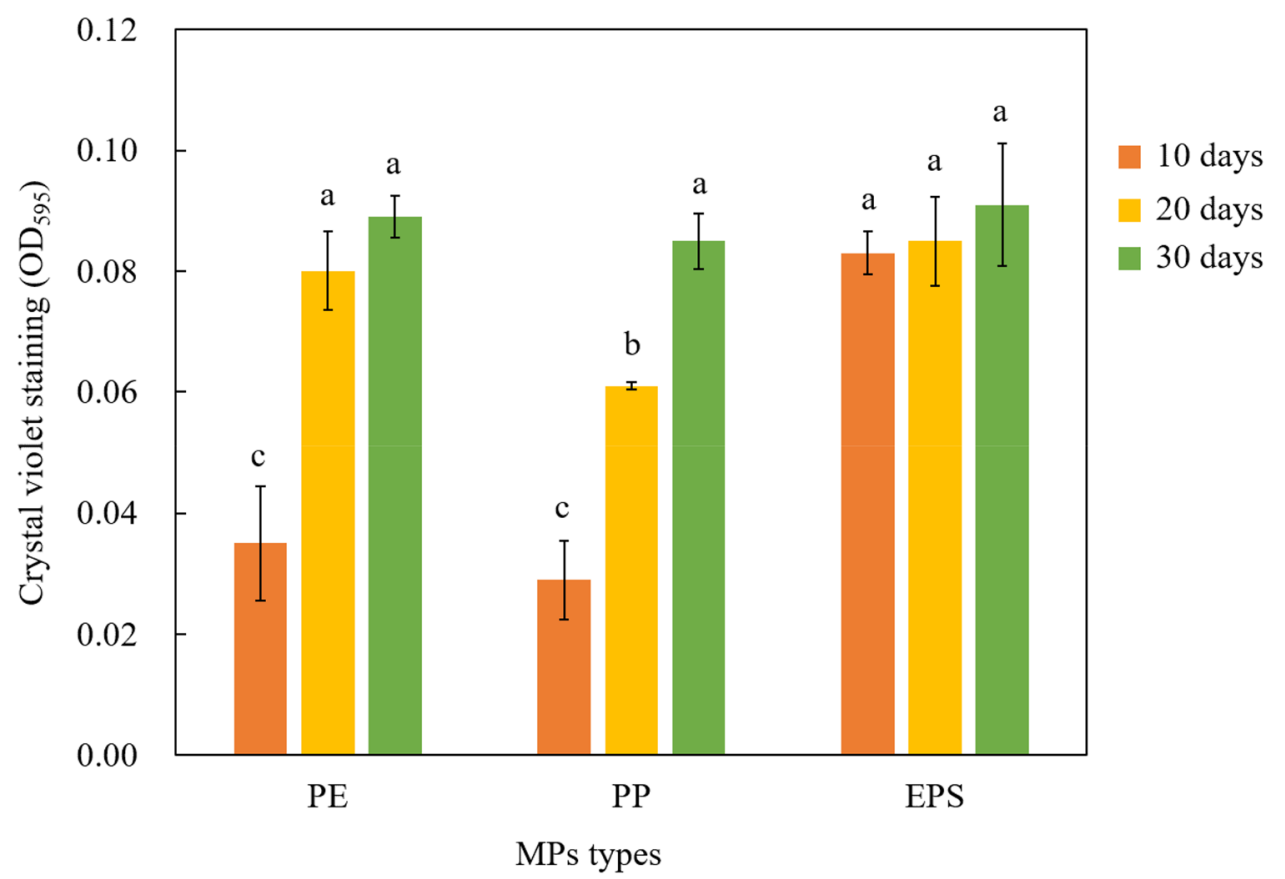



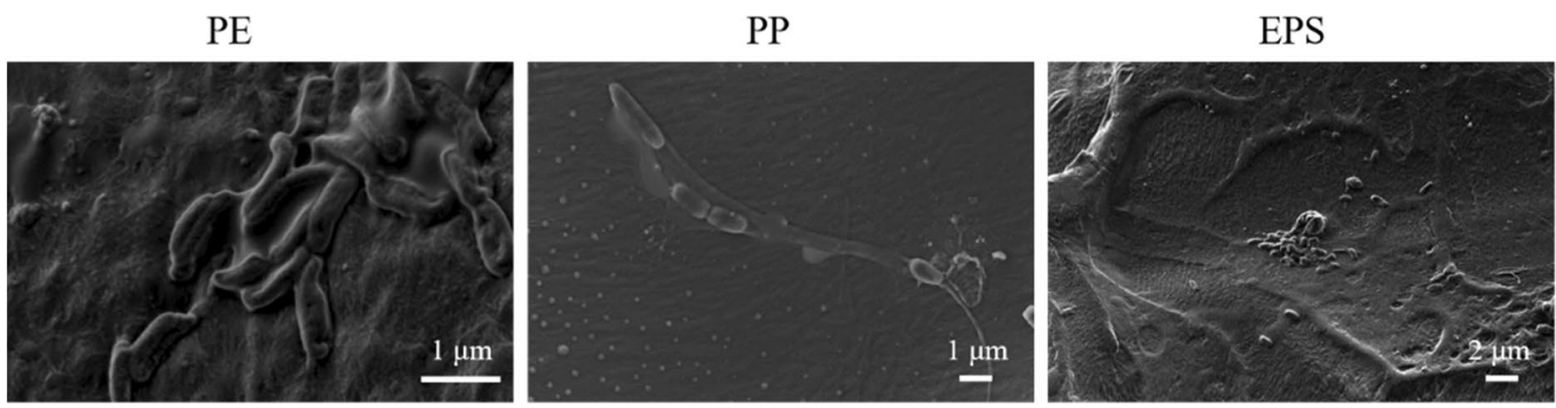

10 days
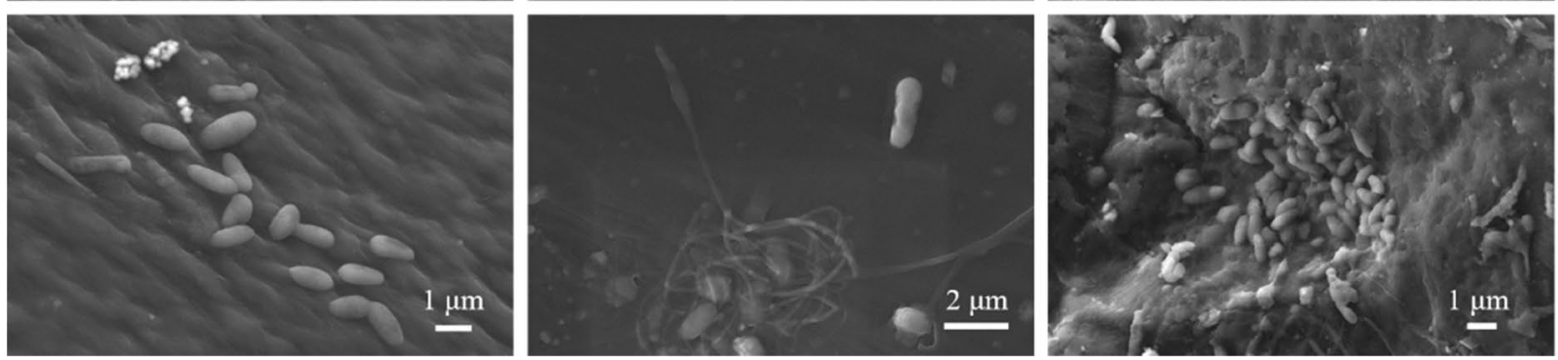

30 days

Fig. 2 SEM images of the biofilms formed after 10 and 30 days on the surface of different types of MPs

(films) samples were subjected to CLSM analysis in this study (Fig. 3). During the early stages of biofilm formation (10 days and 20 days), the biofilms were mainly composed of extracellular polymeric substances (blue fluorescence). As the biofilms developed (30 days), more living bacteria were observed together with the extracellular polymeric substances. This is consistent with the SEM images, indicating that these bacteria may devote part of their resources toward biofilm formation via production of extracellular polymeric substances, possibly at the cost of the colonization speed (Oliveira et al. 2021).

Finally, dynamics of bacterial alpha diversity and community structures of the MPs associated biofilms were profiled by $16 \mathrm{~S}$ rDNA high-throughput sequencing. Shannon,
Ace and Chaol indexes were calculated based on the operational taxonomic unit (OTUs) (Table 1). All the alpha diversity indexes of the three MPs showed significant differences compared with the seawater $(p<0.05)$. In addition, the Shannon, Ace and Chaol indexes showed marked increase at day 30 compared to day 10 for PP $(p<0.05)$, and were also slightly elevated for PE and PP, although it was not statistically significant $(p>0.05)$.

Generally, all the MPs associated biofilms showed a significantly distinct microbial community structure profiles in comparison to the surrounding water (Fig. 4). Phylum Proteobacteria was always the most dominant bacterial population $(65 \%-90 \%)$ in biofilms attached to different microplastics at different incubation times,
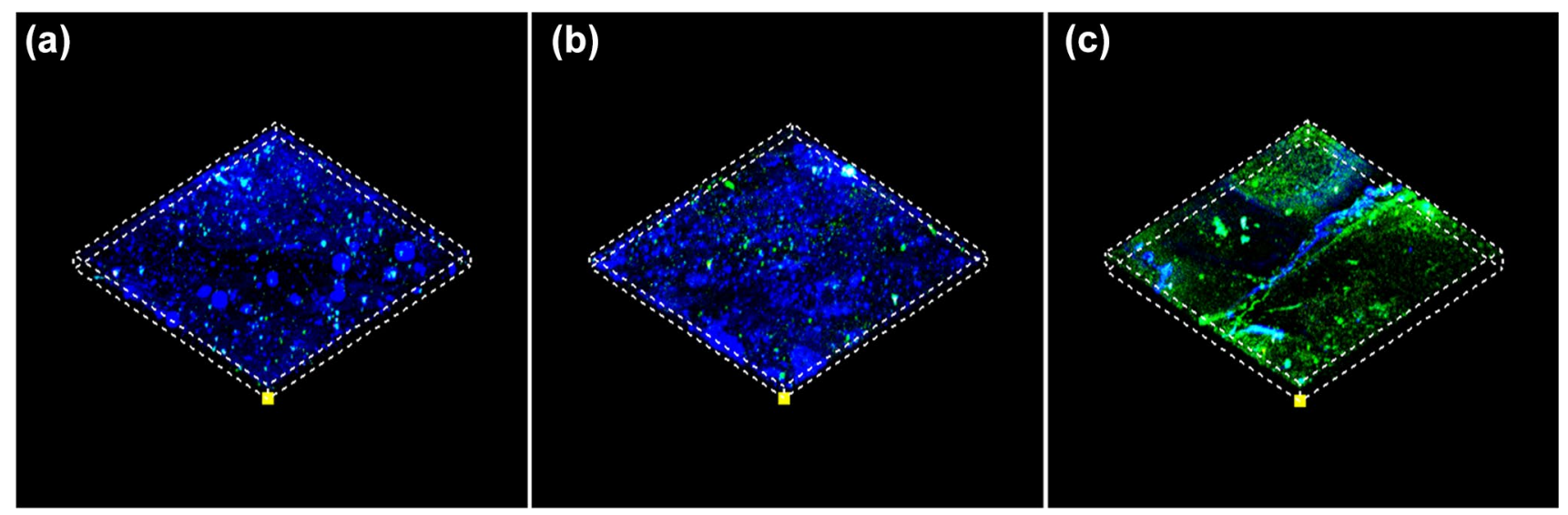

Fig. 3 Merged fluorescent CLSM images of biofilm on the PE surface over time (a: 10 days, b: 20 days, c: 30 days; green signal: living cells stained with SYTO9; red signal: dead cells stained with prodium iodide; blue signal: extracellular polymeric substances stained with Concanavalin A) 
Table 1 Bacterial alpha diversity of the MPs associated biofilms

\begin{tabular}{llcl}
\hline MPs & Shannon & Ace & Chao1 \\
\hline EPS 10 days & $3.59 \pm 0.10 \mathrm{c}$ & $568.80 \pm 24.18 \mathrm{bcd}$ & $562.79 \pm 25.06 \mathrm{bcd}$ \\
EPS 30 days & $4.47 \pm 0.11 \mathrm{ab}$ & $750.22 \pm 43.95 \mathrm{~b}$ & $753.89 \pm 32.99 \mathrm{~b}$ \\
PE 10 days & $3.41 \pm 0.27 \mathrm{c}$ & $396.64 \pm 255.41 \mathrm{de}$ & $390.46 \pm 241.36 \mathrm{de}$ \\
PE 30 days & $3.57 \pm 0.60 \mathrm{c}$ & $493.81 \pm 210.99 \mathrm{cde}$ & $498.57 \pm 219.31 \mathrm{cde}$ \\
PP 10 days & $3.11 \pm 0.09 \mathrm{c}$ & $299.75 \pm 12.53 \mathrm{e}$ & $301.22 \pm 14.55 \mathrm{e}$ \\
PP 30 days & $4.27 \pm 0.21 \mathrm{~b}$ & $685.32 \pm 41.98 \mathrm{bc}$ & $689.31 \pm 34.15 \mathrm{bc}$ \\
Seawater & $4.90 \pm 0.12 \mathrm{a}$ & $1169.74 \pm 43.87 \mathrm{a}$ & $1180.11 \pm 31.96 \mathrm{a}$
\end{tabular}

Different lowercase letters in each column indicate significant differences $(p<0.05)$
Fig. 4 Changes in the bacterial community structure for the MPs associated biofilms: a Relative abundance of bacterial phylum; b Principal coordinate analysis (PCoA) of bacterial profiles in seawater, and different MPs exposed for 10 days and 30 days
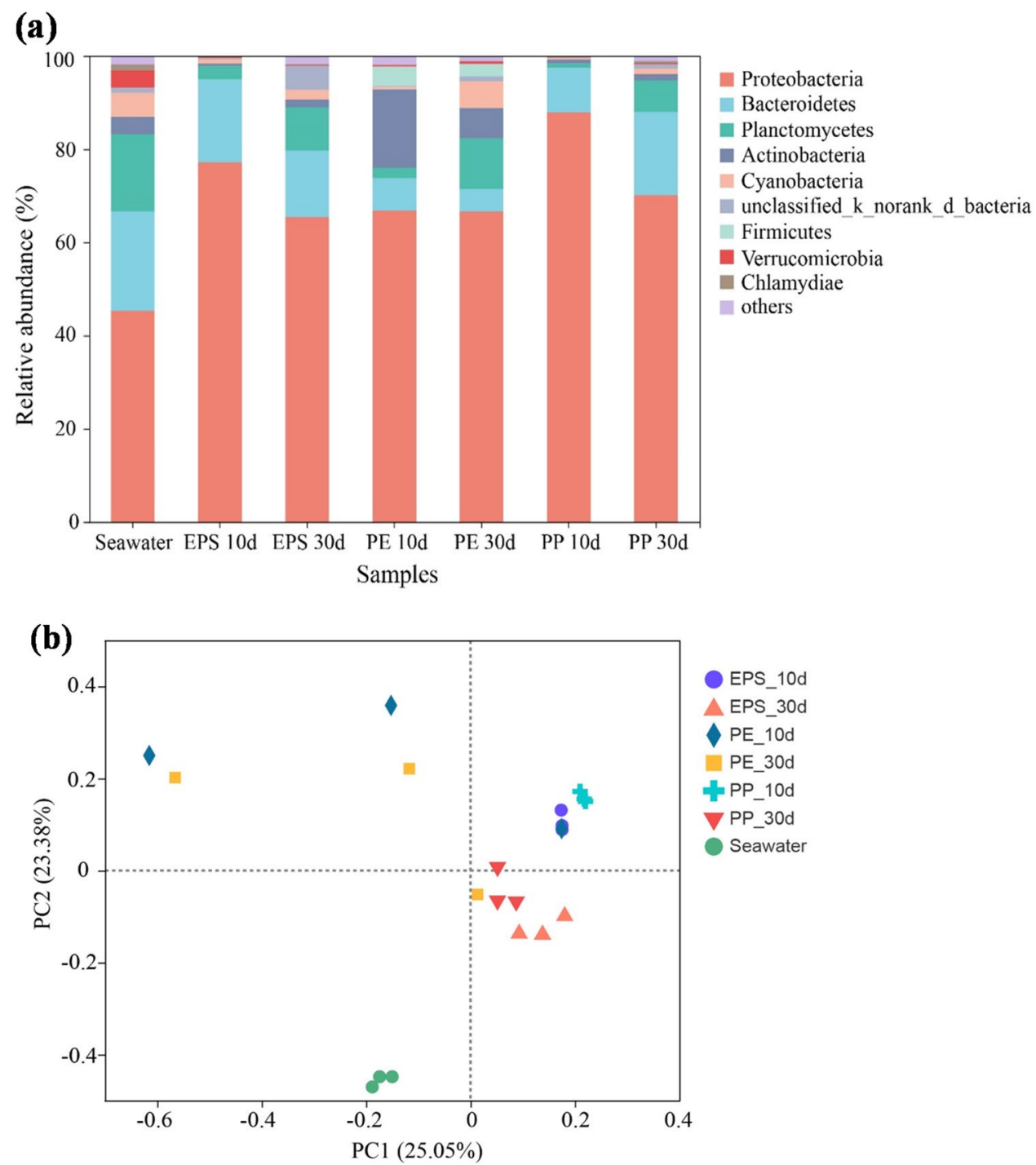

while this percentage was around $45 \%$ in the seawater. This is because some bacterial families from the phylum Proteobacteria, such as Caulobacteraceae, Rhodobacteraceae, Pseudomonadaceae, Erythrobacteraceae from the top 5 families of MPs associated biofilms, are well-known core community members of the "plastisphere" (Fig S1) according to previous studies (Tu et al. 2020b). More important, naturally occurring families including Flavobacteriaceae, Rhodobacteraceae, Pseudomonadaceae and Sphingomonadaceae include members known to degrade complex carbon substrates, even plastic polymers $(\mathrm{Ru}$ et al. 2020). This indicates that these naturally occurring 
strains in the biofilms may have the potential capacity to degrade the MPs.

Variation of FTIR spectra of the PE films were further determined to verify the impacts of biofilm formation on the biodegradation of PE (Fig. S2). After exposure, the PE surfaces showed newly formed peaks at both $1100 \mathrm{~cm}^{-1}$ and $1700 \mathrm{~cm}^{-1}$, which corresponded to the $\mathrm{C}-\mathrm{O}$ and carbonyl $(\mathrm{C}=\mathrm{O})$ group, respectively (Tu et al. 2020b). The incorporation of the $\mathrm{C}-\mathrm{O}$ and $\mathrm{C}=\mathrm{O}$ groups on $\mathrm{PE}$ surface might be attributed to the biofilm formation and the microbial metabolism (Ashar et al. 2020). The intensity of the $\mathrm{C}-\mathrm{O}$ and $\mathrm{C}=\mathrm{O}$ peaks from samples taken at day 20 and 30 was significantly greater than at day 10 and the virgin PE (Fig. S2), indicating an increasing of the hydrophilicity and a decreasing of the surface hydrophobicity of PE. This result was further confirmed by the decreasing of the hydrophilicity as indicated by water contact angle (WCA) on the surface of PE with incubation time (the WCA of pristine PE was $105.8^{\circ}$, and was down to $84.3^{\circ}$ after 30 days). Existing literature documents that the increasing of hydrophilicity facilitates the subsequent biodegradation of microplastics (Roy et al. 2021). In addition, in order to minimize the effects of photo-degradation on the microplastics in this study, the microplastics were packed in the nylon bags to protect against direct sunlight before they were submerged in the glass tank. Thus, the combined results from DNA sequencing, FTIR spectra and WCA provided strong evidence that some of the naturally occurring microbes in the seawater of the Baltic Sea forming biofilms are microplastic degraders.

This study demonstrated the temporal development of biofilm formation and succession on the surface of different microplastics using a microcosm experiment. Incubation time and polymer type were the main factors affecting the biomass, morphology, composition and microbial community structure of MPs associated biofilms. Flavobacteriaceae, Rhodobacteraceae and Pseudomonadaceae are not only the core microbiomes that dominate the plastisphere, but also potential MP-degraders. The incorporation of hydrophilic groups and the increased of hydrophilicity confirmed the degradation of MPs due to the microbial colonization and biofilm formation. Future research should be conducted to further illustrate the roles and mechanisms of biofilm mediated interaction between MPs and microorganisms.

Supplementary Information The online version contains supplementary material available at https://doi.org/10.1007/s00128-021-03333-1.

Acknowledgements This work was funded by the Key Research Program of Frontier Sciences, CAS, China (No. QYZDJSSW-DQC015), and the Sino-German International Cooperation Project, BMBF, Germany (No. 03F0786A). The authors thank Sascha Plewe and Qian Zhou
(IOW) for their support and assistance while working with the SEM, and Chenjie Zhang (YIC) for his assistance in CVA.

\section{References}

Amaral-Zettler LA, Zettler ER, Mincer TJ (2020) Ecology of the plastisphere. Nat Rev Microbiol 18:139-151

Arias-Andres M, Rojas-Jimenez K, Grossart HP (2019) Collateral effects of microplastic pollution on aquatic microorganisms: an ecological perspective. Trac-Trends Anal Chem 112:234-240

Ashar M, Fraser MA, Li J, Wang C, Huang W, Zhang D, Zhang C (2020) Interaction between microbial communities and various plastic types under different aquatic systems. Mar Environ Res 162:105151

Cole M, Lindeque P, Halsband C, Galloway TS (2011) Microplastics as contaminants in the marine environment: a review. Mar Pollut Bull 62:2588-2597

Cunningham EM, Ehlers SM, Dick JTA, Sigwart JD, Linse K, Dick JJ, Kiriakoulakis K (2020) High abundances of microplastic pollution in deep-sea sediments: evidence from Antarctica and the southern ocean. Environ Sci Technol 54:13661-13671

He DF, Luo YM (2020) Microplastics in terrestrial environments: emerging contaminants and major challenges. Springer Nature, Switzerland

Li LZ, Luo YM, Li RJ, Zhou Q, Peijnenburg WJGM, Yin N, Yang J, Tu C, Zhang YC (2020) Effective uptake of submicrometre plastics by crop plants via a crack-entry mode. Nat Sustain 3:929-937

Lobelle D, Cunliffe M (2011) Early microbial biofilm formation on marine plastic debris. Mar Pollut Bull 62:197-200

McCormick A, Hoellein TJ, Mason SA, Schluep J, Kelly JJ (2014) Microplastic is an abundant and distinct microbial habitat in an urban river. Environ Sci Technol 48:11863-11871

Oberbeckmann S, Labrenz M (2020) Marine microbial assemblages on microplastics: diversity, adaptation, and role in degradation. Annu Rev Mar Sci 12:209-232

Ogonowski M, Motiei A, Ininbergs K, Hell E, Gerdes Z, Udekwu KI, Bacsik Z, Gorokhova E (2018) Evidence for selective bacterial community structuring on microplastics. Environ Microbiol 20:2796-2808

Oliveira MM, Proenca AM, Moreira-Silva E, de Castro AM, dos Santos FM, Marconatto L, Medina-Silva R (2021) Biofilms of Pseudomonas and Lysinibacillus marine strains on high-density polyethylene. Microb Ecol 81:833-846

Roy R, Mukherjee G, Das Gupta A, Tribedi P, Sil AK (2021) Isolation of a soil bacterium for remediation of polyurethane and low-density polyethylene: a promising tool towards sustainable cleanup of the environment. 3Biotech 11:29

Ru JK, Huo YX, Yang Y (2020) Microbial degradation and valorization of plastic wastes. Front Microbiol 11:442

Tu C, Zhou Q, Zhang CJ, Liu Y, Luo YM (2020a) Biofilms of microplastics. In: He DF, Luo YM (eds) Microplastics in terrestrial environments: emerging contaminants and major challenges. Springer Nature, Switzerland, pp 299-317

Tu C, Chen T, Zhou Q, Liu Y, Wei J, Waniek JJ, Luo YM (2020b) Biofilm formation and its influences on the properties of microplastics as affected by exposure time and depth in the seawater. Sci Total Environ 734:139237

Van Cauwenberghe L, Vanreusel A, Mees J, Janssen CR (2013) Microplastic pollution in deep-sea sediments. Environ Pollut 182:495-499

Walters W, Hyde ER, Berg-Lyons D, Ackermann G, Humphrey G, Parada A, Gilbert JA, Jansson JK, Caporaso JG, Fuhrman JA, Apprill A, Knight R (2015) Improved bacterial 16S rRNA gene 
(V4 and V4-5) and fungal internal transcribed spacer marker gene primers for microbial community surveys. mSystems 1(1):e00009-15

Wright RJ, Erni-Cassola G, Zadjelovic V, Latva M, Christie-Oleza JA (2020) Marine plastic debris: a new surface for microbial colonization. Environ Sci Technol 54:11657-11672

Wright SL, Ulke J, Font A, Chan KLA, Kelly FJ (2020) Atmospheric microplastic deposition in an urban environment and an evaluation of transport. Environ Int 136:105411

Yan YY, Chen ZH, Zhu FX, Zhu CY, Wang C, Gu C (2020) Effect of polyvinyl chloride microplastics on bacterial community and nutrient status in two agricultural soils. Bull Environ Contam Toxicol. https://doi.org/10.1007/s00128-020-02900-2

Yang J, Yang Y, Wu WM, Zhao J, Jiang L (2014) Evidence of polyethylene biodegradation by bacterial strains from the guts of plasticeating waxworms. Environ Sci Technol 48:13776-13784
Yang Y, Liu W, Zhang Z, Grossart H-P, Gadd GM (2020) Microplastics provide new microbial niches in aquatic environments. Appl Microbiol Biotechnol 104:6501-6511

Zettler ER, Mincer TJ, Amaral-Zettler LA (2013) Life in the "Plastisphere": microbial Communities on Plastic Marine Debris. Environ Sci Technol 47:7137-7146

Zhu FX, Zhu CY, Wang C, Gu C (2019) Occurrence and ecological impacts of microplastics in soil systems: a review. Bull Environ Contam Toxicol 102:741-749

Publisher's Note Springer Nature remains neutral with regard to jurisdictional claims in published maps and institutional affiliations. 


\section{Terms and Conditions}

Springer Nature journal content, brought to you courtesy of Springer Nature Customer Service Center GmbH ("Springer Nature").

Springer Nature supports a reasonable amount of sharing of research papers by authors, subscribers and authorised users ("Users"), for smallscale personal, non-commercial use provided that all copyright, trade and service marks and other proprietary notices are maintained. By accessing, sharing, receiving or otherwise using the Springer Nature journal content you agree to these terms of use ("Terms"). For these purposes, Springer Nature considers academic use (by researchers and students) to be non-commercial.

These Terms are supplementary and will apply in addition to any applicable website terms and conditions, a relevant site licence or a personal subscription. These Terms will prevail over any conflict or ambiguity with regards to the relevant terms, a site licence or a personal subscription (to the extent of the conflict or ambiguity only). For Creative Commons-licensed articles, the terms of the Creative Commons license used will apply.

We collect and use personal data to provide access to the Springer Nature journal content. We may also use these personal data internally within ResearchGate and Springer Nature and as agreed share it, in an anonymised way, for purposes of tracking, analysis and reporting. We will not otherwise disclose your personal data outside the ResearchGate or the Springer Nature group of companies unless we have your permission as detailed in the Privacy Policy.

While Users may use the Springer Nature journal content for small scale, personal non-commercial use, it is important to note that Users may not:

1. use such content for the purpose of providing other users with access on a regular or large scale basis or as a means to circumvent access control;

2. use such content where to do so would be considered a criminal or statutory offence in any jurisdiction, or gives rise to civil liability, or is otherwise unlawful;

3. falsely or misleadingly imply or suggest endorsement, approval, sponsorship, or association unless explicitly agreed to by Springer Nature in writing;

4. use bots or other automated methods to access the content or redirect messages

5. override any security feature or exclusionary protocol; or

6. share the content in order to create substitute for Springer Nature products or services or a systematic database of Springer Nature journal content.

In line with the restriction against commercial use, Springer Nature does not permit the creation of a product or service that creates revenue, royalties, rent or income from our content or its inclusion as part of a paid for service or for other commercial gain. Springer Nature journal content cannot be used for inter-library loans and librarians may not upload Springer Nature journal content on a large scale into their, or any other, institutional repository.

These terms of use are reviewed regularly and may be amended at any time. Springer Nature is not obligated to publish any information or content on this website and may remove it or features or functionality at our sole discretion, at any time with or without notice. Springer Nature may revoke this licence to you at any time and remove access to any copies of the Springer Nature journal content which have been saved.

To the fullest extent permitted by law, Springer Nature makes no warranties, representations or guarantees to Users, either express or implied with respect to the Springer nature journal content and all parties disclaim and waive any implied warranties or warranties imposed by law, including merchantability or fitness for any particular purpose.

Please note that these rights do not automatically extend to content, data or other material published by Springer Nature that may be licensed from third parties.

If you would like to use or distribute our Springer Nature journal content to a wider audience or on a regular basis or in any other manner not expressly permitted by these Terms, please contact Springer Nature at

onlineservice@springernature.com 